\title{
Inhalt
}

EINLEITUNG $\ldots \ldots \ldots \ldots \ldots \ldots \ldots \ldots \ldots \ldots$

DAVID A. WELLBERY

Die Ausblendung der Genese. Grenzen der

systemtheoretischen Reform der Kulturwissenschaften . . . . . . . . . . . . . . 19

DIRK BAECKER

Unbestimmte Kultur . . . . . . . . . . . . . . . . . . . . . . . . . . . . . . . . . 29

ALBRECHT KOSCHORKE

Die Grenzen des Systems und die Rhetorik der Systemtheorie . . . . . . . . . . 49

SUSANNE LÜDEMANN

Beobachtungsverhältnisse.

Zur (Kunst-)Geschichte der Beobachtung zweiter Ordnung . . . . . . . . . 63

RUDOLF HELMSTETTER

Der gordische Knoten von Kultur \& Gesellschaft

und Luhmanns Rasiermesser. Fragen eines fluchenden Ruderers . . . . . . . . . . 77

ANTON SCHÜTZ

Luhmanns unheimliches Argument . . . . . . . . . . . . . . . . . 97

ELENA ESPOSITO

Das Problem der Reflexivität in den Medien und in der Theorie . . . . . . . . . . 113 
BERNHARD J. DOTZLER

Unsichtbare Maschinen - Irritationsbestände

aus der Geschichte der Kybernetik erster Ordnung . . . . . . . . . . . . . . . . 121

\section{FRIEDRICH BALKE}

Dichter, Denker und Niklas Luhmann.

Über den Sinnzwang in der Systemtheorie . . . . . . . . . . . . . . . . 135

LUTZ ELLRICH

,Tragic Choices' - Überlegungen zur selektiven

Wahrnehmung der Systemtheorie am Beispiel des Nationalsozialismus . . . . . . . . . 159

THOMAS WIRTZ

Entscheidung. Niklas Luhmann und Carl Schmitt . . . . . . . . . . . . . . . . 175

GUNTHER TEUBNER

Ökonomie der Gabe - Positivität der Gerechtigkeit:

Gegenseitige Heimsuchungen von System und différance . . . . . . . . . . . . . . 199

\section{ANHANG}

Register. . . . . . . . . . . . . . . . . . . . . . . . 215

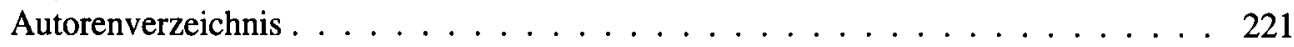

